\title{
A Survey on Voiding Complaints in Women Presenting at a Pelvic Care Center
}

\author{
Heidi Moossdorff-Steinhauser ${ }^{\mathrm{a}} \quad$ Kevin L.J. Rademakers $^{\mathrm{b}} \quad$ Fred Nieman $^{\mathrm{c}}$ \\ Gommert A. van Koeveringe $^{b} \quad$ Bary Berghmans $^{d}$ \\ a Maastricht University, Maastricht; ${ }^{b}$ Department of Urology; 'Department of Clinical Epidemiology and Medical Technology

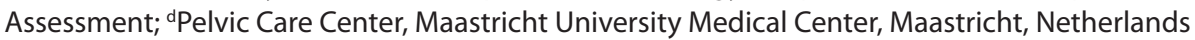

\section{Key Words}

Female $\cdot$ Lower urinary tract symptoms Prevalence •

Self-report $•$ Urinary tract infections

\begin{abstract}
Introduction: This article reports the prevalence of self-reported voiding complaints and the relationship with other pelvic floor and bladder dysfunctions (PFD). Materials and Methods: Women with a variety of PFDs were referred to the pelvic care center. A standardised questionnaire on 6 PFDs was used. Frequencies of patient characteristics, PFDs and voiding complaints were calculated. Cross tabulation was used to investigate correlations and Pearson correlation coefficients to reveal the strength of the association between PFDs and self-reported voiding complaints. Results: Data of 4470 women were included. Prevalence of (self-reported) voiding Lower urinary tract symptoms was 59.5\%. Incomplete bladder emptying is the most prevalent voiding complaint. Self-reported voiding complaints are weakly correlated to age $(r=0.15, p<0.01)$ and have moderate correlation with self-reported recurrent urinary tract infections $(r=$ $0.34, p<0.01$ ), pelvic floor, bladder and bowel complaints.
\end{abstract}

\section{KARGER}

Fax +41613061234

E-Mail karger@karger.com

www.karger.com

\section{(C) 2019 The Author(s)}

Published by S. Karger AG, Basel Upen access

This article is licensed under the Creative Commons AttributionNonCommercial-NoDerivatives 4.0 International License (CC BYNC-ND) (http://www.karger.com/Services/OpenAccessLicense). Usage and distribution for commercial purposes as well as any distribution of modified material requires written permission.
However, the correlation between the feeling of incomplete bladder emptying and the presence of recurrent urinary tract infections is weak $(r=0.06, p=0.02)$. Conclusion: Voiding complaints have a high prevalence and symptom bother in women visiting a pelvic care center.

(c) 2019 The Author(s)

Published by S. Karger AG, Basel

\section{Introduction}

Lower urinary tract symptoms (LUTS) include storage, voiding and post-micturition symptoms [1]. According to earlier studies, the prevalence of LUTS in women is between 45.2 and $76.3 \%$ in the out of hospital population $[2,3]$. Studies about LUTS in women generally focus on storage problems such as urgency, frequency, with or without incontinence and nocturia. However, voiding LUTS in women have been neglected for years.

Voiding LUTS may consist of feeling of incomplete bladder emptying, straining to void, intermittency and slow stream. Incomplete bladder emptying can result in too high post-void residuals (PVR) of urine, increasing

Heidi Moossdorff-Steinhauser

Maastricht University

NL-6202 AZ Maastricht (Netherlands)

E-Mail heidi.moossdorff@maastrichtuniversity.nl 
Table 1. Characteristics: all women (with and without voiding complaints)

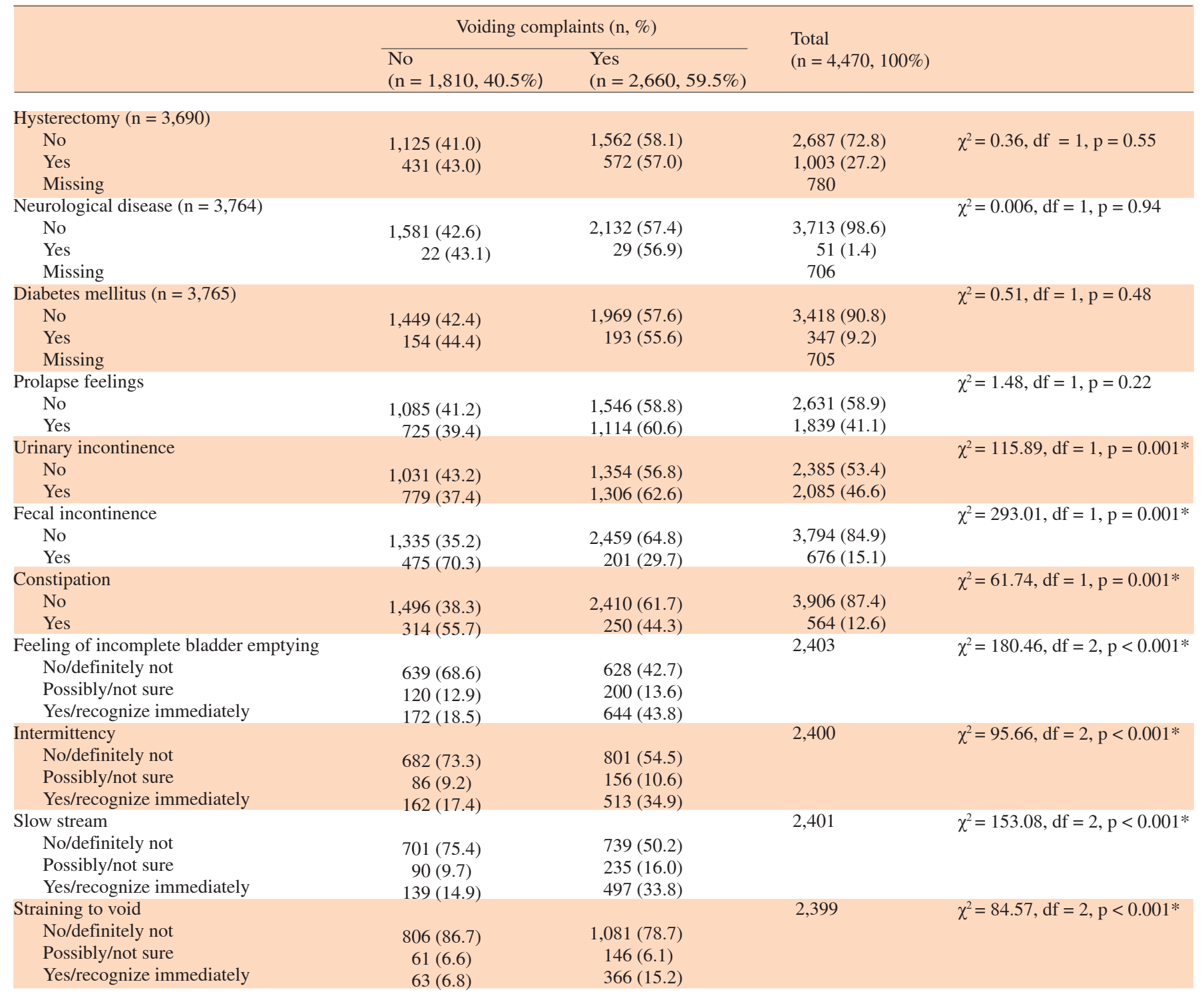

$* \mathrm{p}<0.05$.

the risk of urinary tract infections (UTI) [4]. Voiding symptoms can be due to a plethora of problems including bladder outlet obstruction or detrusor underactivity. The cause of bladder outlet obstruction can be anatomical, neurological and/or functional like, for example, a malignancy, urethral stricture, pelvic organ prolapse (POP), Parkinson's disease, surgery, Fowler's syndrome or dysfunctional voiding. Detrusor underactivity is defined by the International Continence Society as: "a contraction of reduced strength and/or duration, resulting in prolonged bladder emptying, and/or failing to achieve complete bladder emptying within a normal time span" [5].

In the general population the prevalence of incomplete bladder emptying is approximately $35 \%[2,3]$. To date, the prevalence of self-reported voiding complaints was only derived from small cohort studies [6,7]. The objective of this study was to report the prevalence of self-reported voiding complaints in a cohort of adult 
Table 2. Pearson coefficients between self-reported voiding complaints and patient characteristics and voiding symptoms

\begin{tabular}{lcc}
\hline & $\mathrm{r}$ & $\mathrm{p}$ \\
\hline Age & 0.15 & $<0.01 *$ \\
UTI & 0.34 & $<0.01 *$ \\
Hysterectomy & 0.01 & 0.55 \\
Urinary incontinence & 0.06 & $<0.01 *$ \\
POP & 0.02 & 0.22 \\
Constipation & -0.12 & $<0.01 *$ \\
Fecal incontinence & -0.26 & $<0.01 *$ \\
Voiding symptoms & & \\
$\quad$ Feeling of incomplete bladder emptying & 0.27 & $<0.01 *$ \\
$\quad$ Intermittency & 0.20 & $<0.01 *$ \\
$\quad$ Slow stream & 0.25 & $<0.01 *$ \\
$\quad$ Straining to void & 0.18 & $<0.01 *$ \\
\hline$\quad$ *p $<0.05$. & & \\
\end{tabular}

women attending a large pelvic care center. In addition, to assess the relationship between self-reported voiding complaints and other self-reported pelvic floor and bladder dysfunctions, including UTIs. The outcome of this study will increase our understanding of the type and extent of self-reported voiding complaints amongst the female population and the coexistence of voiding disorders with other perceived pelvic floor, bladder and bowel complaints.

\section{Methods}

\section{Database}

Women with a variety of pelvic floor dysfunctions (PFDs) were referred by either the general practitioner or a medical specialist to a pelvic care center. A specialized pelvic care nurse interviewed the patients at first contact about their complaints and perceived severity of the symptoms in the previous 6 months. The triage has been described elsewhere [8]. A standardized self-constructed questionnaire on 6 different PFDs e.g. voiding dysfunction, urinary incontinence, POP, constipation, fecal incontinence and sexual dysfunction, was used. Subjective symptom severity of the PFDs was measured with the numeric rating scale on a scale from 0 to $10(0=$ no complaints and $10=$ most severe complaints $)$. A score of 5 or higher was considered clinically relevant. The numeric rating scale is a reliable and responsive measurement instrument [9]. The urological part of the questionnaire consisted of 24 questions regarding urinary incontinence and voiding symptoms. Questions about urinary incontinence included 'do you lose urine during laughing, coughing, during walking or when you hear running water', but also asked about how urinary incontinence was perceived. The feeling of incomplete bladder emptying, intermittency, slow stream and, straining to void are examples of questions concerning voiding dysfunctions.

Survey on Voiding Complaints in Women

\section{Statistics}

Statistical analysis included an assessment of patient characteristics and the prevalence of PFDs and voiding complaints. PFDs were defined as the complaints of POP, urinary incontinence and constipation. The voiding complaints were defined as feeling of incomplete bladder emptying, intermittency, slow stream and straining to void. Cross tabulation (Chi-square statistics) was used to investigate correlations between PFDs and voiding complaints. Pearson correlation coefficients between voiding complaints and PFDs variables were calculated to reveal the strength of the association.

An exploratory factor analysis was performed and Cronbach's alpha was calculated to test the internal cohesiveness, the unidimensionality and the additivity of the 4 voiding problem items (feeling of incomplete bladder emptying, intermittency, slow stream and straining to void) with respect to constructing a scale. A p-value of less than 0.05 was considered statistically significant. For all data analysis IBM SPSS-pc version 22 was used.

\section{Results}

The data were collected from 4,470 female patients attending the Pelvic Care Center Maastricht between March 2005 and March 2013. Prevalence of (subjective) voiding LUTS in these patients was 2,660 (59.5\%). The mean age was $57 \pm 16.2$ years (range $14-95$ years). The majority of the women with voiding complaints reported a symptom severity of 5 , on a scale $0-10(98.2 \%)$. Feeling of incomplete bladder emptying (43.8\%) was the most prevalent symptom, followed by intermittency (34.9\%), slow stream (33.8\%) and straining to void (15.2\%). Table 1 shows the patient characteristics, voiding complaints and associations with prevalence of voiding LUTS.

There was no difference between women with or without self-reported voiding complaints regarding having had a hysterectomy, neurological disease, diabetes mellitus or the feeling of genitourinary prolapse.

Pearson's $r$ data analysis shows that self-reported voiding complaints are weakly correlated with age $(\mathrm{r}=$ $0.15, \mathrm{p}<0.01)$ and have a moderate correlation with the presence of recurrent UTI $(r=0.34, p<0.01)$. Fecal incontinence and constipation appear to be negatively correlated (table 2) with voiding complaints: the prevalence of one dysfunction appears to preclude the prevalence of the other. However, the correlation between the feeling of incomplete bladder emptying and the presence of recurrent UTIs is weak $(r=0.06, p=0.02)$.

Figure 1 presents the combined occurrence of the responses to different self-reported questions within the spectrum of voiding complaints. A total of $9.6 \%$ women reported having 3 voiding complaints (a slow stream, intermittency and the feeling of incomplete bladder emptying), $7.8 \%$ reported presence of all 4 complaints (fig. 1). 


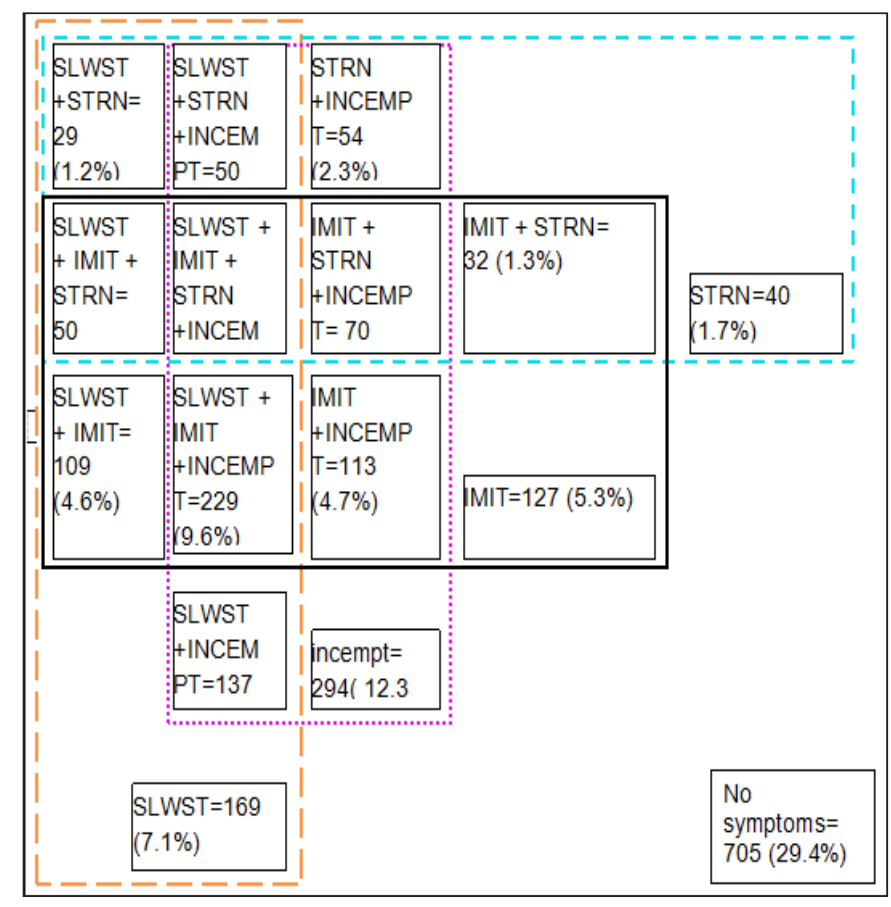

Fig. 1. Co-existing voiding symptoms in women with voiding complaints $($ Yellow $=$ SLWST $=$ slow stream; Magenta $=$ INCEMPT = feeling of incomplete bladder emptying; Cyan $=$ STRN $=$ straining to void; Black = IMIT $=$ intermittency).

In 2,395 female patients, the data relating to the 4 voiding complaints were subjected to a factor analysis to test the internal cohesiveness, unidimensionality and additivity of these items with respect to the primary factor (the first principal component). This only explains $47.3 \%$ of the variance of internal correlation between the 4 items. In addition, Cronbach's alpha on the 4 items of the presumed scale is very low (0.63). One of the conclusions of further psychometric analysis is that the number of items appears to be too low to construct a reliable scale.

\section{Discussion}

This research takes the lead in analyzing self-reported voiding LUTS in a large cohort of 4,470 women presenting with different kinds of PFDs at a pelvic care center. In this cohort of women, $59.5 \%$ reported voiding problems. This is in line with the $61.7 \%$ reported by Groutz et al. [10] on prevalence of self-reported voiding problems in women presenting in a urogynecology clinic. In the general population the prevalence of voiding LUTS ranges
$5.2-34 \%$ [11-13]. Over $98 \%$ of the women in this cohort with self-reported voiding problems perceived a symptom bother of 5 or higher on the numeric rating scale. This high prevalence and symptom bother is in strong contrast to the usual care and medical attention given in clinical practice and in research regarding voiding LUTS in women.

The feeling of incomplete bladder emptying was the most frequently mentioned symptom, followed by intermittency, slow stream and straining to void. The sequence is comparable to the general female population [10]. In men, in the general population, the sequence is slightly different with the feeling of incomplete bladder emptying as the most frequently reported symptom, the second being slow stream followed by intermittency and straining to void as the least frequently mentioned symptom $[2,13,14]$. Factor analysis showed that the 4 questions on voiding LUTS generally used in clinical practice are unreliably insufficient to identify and define the nature and extent of patient's experience and/or bother of voiding problems. The Bristol female lower urinary tract symptoms (BFLUTS) questionnaire has been developed to assess female LUTS and evaluate treatment outcomes. However, in contrast to the BFLUTS long form, the more recommended BFLUTS short form contains no question on the feeling of incomplete bladder emptying. As the feeling of incomplete bladder emptying is the most frequently mentioned symptom in our cohort of women with LUTS, it is striking that such a question is non-existing in the BFLUTS. Thus we would advocate that a valid question regarding this issue should be added to the BFLUTS.

With regard to age, our study showed a weak correlation between self-reported voiding LUTS and age. This is in line with the general population [15-17].

In this group of people, no association between voiding LUTS and self-reported symptom of POP was found. This might be explained by the fact that women with pelvic organ prolapse quantification (POP-Q) stage I and II report only few symptoms or bother of their prolapse $[18,19]$. On the other hand, some other studies have shown that objectively diagnosed POP is significantly related with voiding LUTS in women visiting a urogynecology clinic [20,21]. Despite this, Slieker-ten Hove et al. [19] found that obstructed micturition was not related to any POP-Q stage in the general population.

The current guidelines on UTI of the European Urological Association advises the exclusion of residual urine in recurrent uncomplicated UTIs in adult women. 
In our cohort there is a moderate correlation between self-reported voiding LUTS and UTIs during the last 12 months. However, although the feeling of incomplete bladder emptying and having had UTI is significant, it shows only a very weak correlation. This is in line with research showing that PVR urine is not associated with UTI for nursing home residents [22] and the symptom of incomplete bladder emptying is not associated with high PVR volume [23]. Now it seems that PVR and UTI are not related for all age groups, it is interesting to investigate more extensively the clinical value and relevancy of history-taking questions regarding voiding dysfunction and objective measurement of PVR in relation to the development and occurrence of UTI. This can contribute to the fine-tuning of the diagnostic and treatment algorithm and cost effectiveness of treating women with UTI [24].

Constipation and fecal incontinence were negatively correlated with self-reported voiding LUTS. This indicates that women with voiding complaints hardly suffer from constipation or fecal incontinence and vice versa.

Factor analysis showed that approximately $25-30 \%$ of the patients cannot recognize their voiding problems in any of the 4 items (feeling of incomplete bladder emptying, intermittency, slow stream and, straining to void). Previously it was reported that the question of the feeling of incomplete bladder emptying has a low predictive value for the evaluation of female voiding dysfunction [25] and that women with higher bother of obstructed symptoms do not increase the sensitivity and specificity of the questions for obstructed voiding symptoms regarding urinary retention or elevated PVR [26]. This shows a profound lack of sensitivity of scale and an urgent need for additional and more sensitive items.

Voiding LUTS and urinary incontinence are weak but significantly related. This outcome is to be expected as the epidemiology of LUTS study, a population based survey, reported that $46 \%$ of women with LUTS have symptoms from more than one symptom group [12]. For the clinic this means that women who are referred because of any LUTS should monitored for all problems in the LUTS spectrum.

General limitations of this study are its retrospective nature, making it difficult to draw conclusions with regard to causality. In addition, the questions selected by health care professionals did not consist of validated questionnaires. A last limitation of the study is the general lack of knowledge on this topic of voiding dysfunction in women. Therefore, there are some suggestions for future research and clinical practice. Prospective studies regarding voiding dysfunctions in women are warranted.
Research on comparison of subjective symptoms with objective results of urodynamic investigation to investigate whether subjective symptoms are an indicator for objective signs and the construction of a sensitive/discriminative and more specific questionnaire related to female LUTS.

\section{Conclusion}

Voiding complaints have a high prevalence and symptom bother in women visiting a pelvic care center. Incomplete bladder emptying is the most prevalent voiding complaint. The feeling of incomplete bladder emptying has a weak correlation with POP complaints and having had UTI during the last 12 months.

\section{Acknowledgement}

This study was supported by Astellas grant. 


\section{References}

$\checkmark 1$ Haylen BT, de Ridder D, Freeman RM, Swift SE, Berghmans B, Lee J, Monga A, Petri E, Rizk DE, Sand PK, Schaer GN: An International Urogynecological Association (IUGA)/International Continence Society (ICS) joint report on the terminology for female pelvic floor dysfunction. Neurourol Urodyn 2010;29:4-20.

$\checkmark 2$ Irwin DE, Kopp ZS, Agatep B, Milsom I, Abrams P: Worldwide prevalence estimates of lower urinary tract symptoms, overactive bladder, urinary incontinence and bladder outlet obstruction. BJU Int 2011;108:11321138.

-3 Coyne KS, Sexton CC, Thompson CL, Milsom I, Irwin D, Kopp ZS, Chapple CR, Kaplan S, Tubaro A, Aiyer LP, Wein AJ: The prevalence of lower urinary tract symptoms (LUTS) in the USA, the UK and Sweden: results from the Epidemiology of LUTS (EpiLUTS) study. BJU Int 2009;104:352-360.

-4 Haylen BT, Lee J, Husselbee S, Law M, Zhou J: Recurrent urinary tract infections in women with symptoms of pelvic floor dysfunction. Int Urogynecol J Pelvic Floor Dysfunct 2009;20:837-842.

5 Abrams P, Cardozo L, Fall M, Griffiths D, Rosier P, Ulmsten U, van Kerrebroeck P, Victor A, Wein A: The standardisation of terminology of lower urinary tract function: report from the Standardisation Sub-committee of the International Continence Society. Am J Obstet Gynecol 2002;187:116-126.

6 Gotoh M, Yoshikawa Y, Ohshima S: Pathophysiology and subjective symptoms in women with impaired bladder emptying. Int J Urol 2006;13:1053-1057.

7 Wyndaele M, De Winter BY, Pelckmans PA, De Wachter S, Van Outryve M, Wyndaele JJ: Exploring associations between lower urinary tract symptoms (LUTS) and gastrointestinal (GI) problems in women: a study in women with urological and GI problems vs a control population. BJU Int 2015;115:958-967.

-8 Berghmans B, Nieman F, Leue C, Weemhoff M, Breukink S, van Koeveringe G: Prevalence and triage of first-contact complaints on pelvic floor dysfunctions in female patients at a Pelvic Care Centre. Neurourol Urodyn 2016;35:503-508.
-9 Hjermstad MJ, Fayers PM, Haugen DF, Caraceni A, Hanks GW, Loge JH, Fainsinger R, Aass N, Kaasa S: Studies comparing Numerical Rating Scales, Verbal Rating Scales, and Visual Analogue Scales for assessment of pain intensity in adults: a systematic literature review. J Pain Symptom Manage 2011;41:1073-1093.

10 Groutz A, Gordon D, Lessing JB, Wolman I, Jaffa A, David MP: Prevalence and characteristics of voiding difficulties in women: are subjective symptoms substantiated by objective urodynamic data? Urology 1999;54:268272.

11 Irwin DE, Milsom I, Hunskaar S, Reilly K, Kopp Z, Herschorn S, Coyne K, Kelleher C, Hampel C, Artibani W, Abrams P: Population-based survey of urinary incontinence, overactive bladder, and other lower urinary tract symptoms in five countries: results of the EPIC study. Eur Urol 2006;50:13061314.

-12 Sexton CC, Coyne KS, Kopp ZS, Irwin DE, Milsom I, Aiyer LP, Tubaro A, Chapple CR, Wein AJ: The overlap of storage, voiding and postmicturition symptoms and implications for treatment seeking in the USA, UK and Sweden: EpiLUTS. BJU Int. 2009;103(Suppl 3):12-23.

13 Moreira ED Jr, Neves RC, Neto AF, Duarte FG, Moreira TL, Lobo CF, Glasser DB: A population-based survey of lower urinary tract symptoms (LUTS) and symptom-specific bother: results from the Brazilian LUTS epidemiology study (BLUES). World J Urol 2013;31:1451-1458.

14 Wang Y, Hu H, Xu K, Wang X, Na Y, Kang $\mathrm{X}$ : Prevalence, risk factors and the bother of lower urinary tract symptoms in China: a population-based survey. Int urogynecol $\mathrm{J}$ 2015;26:911-919.

15 Zhang L, Zhu L, Xu T, Lang J, Li Z, Gong J, Liu Q, Liu X: A population-based survey of the prevalence, potential risk factors, and symptom-specific bother of lower urinary tract symptoms in adult Chinese women. Eur Urol 2015;68:97-112.

16 Homma Y, Yamaguchi O, Hayashi K: Epidemiologic survey of lower urinary tract symptoms in Japan. Urology 2006;68:560564.
17 Zumrutbas AE, Bozkurt AI, Tas E, Acar CI, Alkis O, Coban K, Cetinel B, Aybek Z: Prevalence of lower urinary tract symptoms, overactive bladder and urinary incontinence in western Turkey: results of a population-based survey. Int J Urol 2014;21:1027-1033.

18 Swift SE, Tate SB, Nicholas J: Correlation of symptoms with degree of pelvic organ support in a general population of women: what is pelvic organ prolapse? Am J Obstet Gynecol 2003;189:372-377.

19 Slieker-ten Hove MC, Pool-Goudzwaard AL, Eijkemans MJ, Steegers-Theunissen RP, Burger CW, Vierhout ME: The prevalence of pelvic organ prolapse symptoms and signs and their relation with bladder and bowel disorders in a general female population. Int Urogynecol J Pelvic Floor Dysfunct 2009;20:1037-1045.

20 Haylen BT, Krishnan S, Schulz S, Verity L, Law M, Zhou J, Sutherst J: Has the true prevalence of voiding difficulty in urogynecology patients been underestimated? Int Urogynecol J Pelvic Floor Dysfunct 2007;18:53-56.

21 Digesu GA, Chaliha C, Salvatore S, Hutchings A, Khullar V: The relationship of vaginal prolapse severity to symptoms and quality of life. BJOG 2005;112:971-976.

22 Omli R, Skotnes LH, Mykletun A, Bakke AM, Kuhry E: Residual urine as a risk factor for lower urinary tract infection: a 1-year follow-up study in nursing homes. J Am Geriatr Soc 2008;56:871-874.

23 Al-Shahrani M, Lovatsis D: Do subjective symptoms of obstructive voiding correlate with post-void residual urine volume in women? Int Urogynecol J Pelvic Floor Dysfunct 2005; 16:12-14.

24 Naber KG, Bergman B, Bishop MC, Bjerklund-Johansen TE, Botto H, Lobel B, Jinenez Cruz F, Selvaggi FP: EAU guidelines for the management of urinary and male genital tract infections. Urinary Tract Infection (UTI) Working Group of the Health Care Office (HCO) of the European Association of Urology (EAU). Eur Urol 2001;40:576-588.

25 Jeon S, Yoo EH: Predictive value of obstructive voiding symptoms and objective bladder emptying tests for urinary retention. J Obstet Gynaecol 2012;32:770-772.

26 Lowenstein L, Anderson C, Kenton K, Dooley Y, Brubaker L: Obstructive voiding symptoms are not predictive of elevated postvoid residual urine volumes. Int Urogynecol J Pelvic Floor Dysfunct 2008;19:801-804. 